Article

\title{
Forecasting the Allocative Efficiency of Carbon Emission Allowance Financial Assets in China at the Provincial Level in 2020
}

\author{
Shihong Zeng ${ }^{1,3, *}$, Yan Xu ${ }^{1,2,3}$, Liming Wang ${ }^{1,3,4, *}$, Jiuying Chen ${ }^{1,3, *}$ and Qirong $\mathrm{Li}^{1}$ \\ 1 Economics \& Management School, Beijing University of Technology, Beijing 100124, China; \\ qiqiqi0406@163.com \\ 2 Changping North Seven Branches, Beijing Branch, Agricultural Bank of China Co., LTD., \\ Beijing 102209, China \\ 3 Finance and Economics Development Research Center, Economic Management School, \\ Beijing University of Technology, Beijing 100124, China; xuyanfuturehope@126.com \\ 4 Irish Institute for Chinese Studies, University College Dublin, Belfield, Dublin D4, Ireland \\ * Correspondence: zengshihong@bjut.edu.cn (S.Z.); liming.wang@ucd.ie (L.W.); 13552055980@139.com (J.C.); \\ Tel.: +86-133-7173-1030 (S.Z.); +353-1-716-3000 (L.W.); +86-135-5205-5980 (J.C.)
}

Academic Editor: Carl-Fredrik Lindberg

Received: 12 February 2016; Accepted: 22 April 2016; Published: 4 May 2016

\begin{abstract}
As the result of climate change and deteriorating global environmental quality, nations are under pressure to reduce their emissions of greenhouse gases per unit of GDP. China has announced that it is aiming not only to reduce carbon emission per unit of GDP, but also to consume increased amounts of non-fossil energy. The carbon emission allowance is a new type of financial asset in each Chinese province and city that also affects individual firms. This paper attempts to examine the allocative efficiency of carbon emission reduction and non-fossil energy consumption by employing a zero sum gains data envelopment analysis (ZSG-DEA) model, given the premise of fixed $\mathrm{CO}_{2}$ emissions as well as non-fossil energy consumption. In making its forecasts, the paper optimizes allocative efficiency in 2020 using 2010 economic and carbon emission data from 30 provinces and cities across China as its baseline. An efficient allocation scheme is achieved for all the provinces and cities using the ZSG-DEA model through five iterative calculations.
\end{abstract}

Keywords: carbon emission allowance; non-fossil fuels; efficiency; zero sum gains data envelopment analysis (ZSG-DEA); iteration

\section{Introduction}

The carbon emission allowance is a new type of financial asset. This article addresses the new type of financial asset allocative efficiency in each Chinese province and city, which we define as the mix of carbon emission reductions and increases across provinces and cities that must be calculated to achieve reach efficient frontiers. In other words, the most efficient region is that with the lowest energy consumption and $\mathrm{CO}_{2}$ emission levels but with the same GDP and population values that it had with no environmental constraints. As an accompaniment to China's rapid economic growth, greenhouse gas emissions have caused serious pollution that has negatively affected the nation's ecology and marginalized its natural environment. As a result, China is facing critical problems that must be solved, and studies of carbon emission resulting from energy consumption focus on questions involving how to achieve reasonable emission reductions while balancing the relationship between economic development and environmental concerns. China's government has committed to reducing its carbon emission per unit of GDP by 40\%-50\% during the 2005-2020 period. During this same period, non-fossil energy consumption is targeted to account for $15 \%$ of total primary energy consumption. 
Non-fossil energy includes wind-generated energy, water-generated energy, nuclear energy, and solar power. The purpose of these reduction targets is to limit overall emissions and achieve positive environmental effects. Although the national target for overall emissions has been set, the key problem that remains is how to apportion the total target effectively, fairly, justly and reasonably among China's provinces and cities in the face of the huge disparities in economic development, energy structures and $\mathrm{CO}_{2}$ emissions and emission schemes that characterizes the different regions. Thus, taking the appropriate related factors into account to achieve allocative efficiency and to maximize effectiveness is a formidable task for China. As of 14 December 2015, seven provinces and cities in China-Shenzhen, Shanghai, Beijing, Guangdong, Tianjin, Chongqing and Hubei-initiated carbon emissions trading schemes. Nonetheless, it is important to know how to allocate carbon allowances to make trading them effective and efficient in China's 30 provinces and cities.

\section{Literature Review}

\subsection{Carbon Allowance Allocation}

A carbon allowance trading scheme attempts to solve environmental problems by using market forces to more effectively allocate resources and to eliminate negative externalities. However, the calculations involved in allocating the initial rights for carbon emissions are pivotal in their impact on transactional efficiency. Therefore, further studies of allocating carbon allowances are both necessary and productive.

From the perspective of government policies, Ding and Feng [1] considered both domestic and international factors in their evaluation of the different modes of carbon allowance allocation and the policy implications associated with each. These authors proposed that China should set up a free allocation mode based on historical data at an early stage but that a paid auction-based mode should be established at a later stage. Sun and Ma [2] compared the advantages and disadvantages of existing initial allocation methods and analysed the current main carbon emission trading schemes that have been implemented all over the world. Based on the results of their research, these authors suggested that a fixed proportion of the free carbon emission allowance should be assigned when a trading scheme is initially established and that it should be further transformed stage-by-stage to gradually reduce the proportion of free allowances until trading is conducted exclusively on an auction basis.

In terms of the allocation modes of carbon emissions, Yin and Cui [3] proposed an allocation scheme based on GDP per capita and energy consumption per GDP. Moreover, Wang Yigang [4] justified a flexible allocation scheme based on ensuring development rights.

With regard to research approaches to allocating carbon allowances, Jiang Jingjing [5] developed a mechanism (and an experiment) for carbon allowance allocation in the Shenzhen manufacturing sector by analyzing the grandfathering allocation mode of Europe's carbon trading scheme-using the condition of incomplete information as its theoretical basis-and by applying limited rational assumptions and repeated game theories. Cong Ronggang [6] suggested a multi-agent carbon allocation auction model (CAAM) based on the auction mechanism of the EU's carbon market and investigated whether the clearing auction price should take the form of uniform pricing or discriminatory pricing. Wang and Li [7] proposed a new data envelopment analysis carbon emissions allocation (DEA-CEA) model on the basis of data envelopment analysis (DEA) methodology. These authors considered the issue of $\mathrm{CO}_{2}$ emissions distribution to be a resource allocation problem in which the total amount is controlled and regarded efficiency as a priority and the per capita amount as a restraint when allocating national total emissions to each province.

To conclude, although there are significant differences in carbon allowance schemes among different countries, there are lessons that these countries can learn from one another. Additionally, allocation benchmarks and research methods vary from country to country based on countries' specific conditions. In general, China is considered to be in the primary stages of establishing a carbon 
allowance system, although its conditions differ from those of other countries. Therefore, further studies are required to establish a suitable and efficient carbon allowance system in China.

\subsection{Carbon Allowance Allocation Based on Efficiency}

The first and most prominent system for regulating carbon emissions is the European Union Emissions Trading Scheme (EU ETS). We examine the effectiveness of the EU ETS in terms of a cap-and-trade system. When it was first established, its efficiency was studied on the macro level. Rogge and Hoffmann [8] believed that the impact of the EU ETS on corporate $\mathrm{CO}_{2}$ culture and routines would pave the way for a transition to a low-carbon innovation system for power generation technologies. Sandoff and Schaad [9] conducted a survey and found that although Swedish companies have shown significant interest in reducing emissions, these companies have not paid close attention to the pricing mechanism of market-based instruments. If this praxis is widespread within the European trading sector, it might seriously and negatively impact system efficiency. Zhang and Wei [10] found that previous research results do not indicate that the EU ETS has had significant economic effects on energy technology investment. The enterprise competitiveness loss caused by the EU ETS has not been strong, but it may become stronger in the future. In later studies, efficiency was studied at the micro level. Moreover, different streams in the literature found that the macro-distribution of carbon allowance assets and $\mathrm{EU} \mathrm{CO}_{2}$ allowance price volatility exerted different effects on the stock market. Oestreich and Tsiakas [11] found that on average, firms that received free carbon emission allowances under the EU ETS significantly outperformed firms that did not, as measured by German stock returns. There was no significant value impact from firms' allowance trading activity or from the pass-through of carbon-related production costs (carbon leakage) [12]. While firms reduced their environmental costs, stock prices also fell for firms in both carbon- and electricity-intensive industries within the EU when the $\mathrm{EU} \mathrm{CO}_{2}$ allowance price dropped 50 per cent in late April 2006 [13].

Most efficiency studies are conducted by employing a variety of input-output models, which leads to the problem of assessing the efficiencies of multiple inputs and outputs of the same types of decision-making units (DMUs), which is why the DEA model is widely used in this context [14]. In comparison with traditional DEA models that presume that output is the expected output (i.e., the larger the output is, the more effective the decision unit is), carbon emissions are regarded as non-expected output, i.e., the smaller the output, the more effective the decision unit is. The DEA model with non-expected output is commonly used in the analysis of environmental efficiency. Zofio and Prieto [15] evaluated environmental efficiency among Organization for Economic Co-operation and Development (OECD) countries by taking carbon dioxide emissions as the non-expected output. Lozano and Gutierrez [16] examined the correlations between GDP, carbon emissions and energy consumption with the distance function method of the DEA model by taking both carbon emissions and energy consumption as the non-expected output.

The non-expected output is independent of DMUs, and each decision unit is also independent of the other decision units. However, with regard to the rights allocations of carbon emissions, the amount of emissions between each decision unit is dependent because there is a fixed amount of available emission rights, i.e., it is a zero sum game (ZSG). When a unit increases or reduces its carbon emissions to achieve greater efficiency, the other DMUs must correspondingly decrease or increase the same amount of carbon emissions to maintain the ZSG.

Lins and Gomes et al. [17] proposed a zero sum gains data envelopment analysis (ZSG-DEA) model to adjust to non-expected output based on the DEA efficiency value of the DMU. Lin and Ning [18] assessed the allocation outcomes of EU countries' carbon emission rights in 2009 based on a ZSG-DEA model. Sun Zuoren et al. [19] investigated the weak disposability of non-expected output and the restraint conditions of the total amount of energy consumption by employing the ZSG-DEA model. The results were used to formulate the allocation of energy efficiency index of the "12th Five Year Plan" in China. Wu et al. [20] studied the allocative efficiency of PM2.5 emission rights based on a zero sum gains DEA model. Pang et al. [21] studied the reallocation of carbon emission allowance with 
regard to all the countries participating in the Kyoto Protocol. Wang et al. [22] investigated the regional allocation of $\mathrm{CO}_{2}$ emissions allowance among Chinese provinces, whereas Miao et al. [23] investigated the efficient allocation of $\mathrm{CO}_{2}$ emissions in China.

This paper differs from those of Wang et al. [22] and Miao et al. [23] by focussing its investigation on the allocation of the $\mathrm{CO}_{2}$ emissions allowance among China's provinces based on China's real 2010 carbon emission data, which is used as a benchmark. This paper is also distinguished from references [24-36], which did not use the ZSG-DEA model and/or did not research the $\mathrm{CO}_{2}$ emissions allowance among China's provinces. Instead, this paper attempts to measure the expected efficiency of carbon emissions allocation in 2020 in China by employing the ZSG-DEA model and further investigates how to establish an efficient allocation under the conditions of fixed total carbon emission rights based on the calculated parameter results.

The contribution of this paper to policy making is as follows: policy makers should adjust the distribution of carbon allowance to achieve the multiple goals of carbon emission reduction and non-fossil energy consumption in different areas in China. Simultaneously, fairness can be achieved among all provinces and cities at the new ZSG-DEA frontier by consider GDP and population (POP) as factors.

\section{Empirical Results and Discussion}

DEAP2.1 software and an Excel planning method were used to solve the original DEA and ZSG-DEA efficiency. The last column of Table 1 presents the results of the original DEA efficiency for 2020, which reveals that the average initial distribution efficiency is 0.731 , i.e., a medium-level average efficiency, and that the differences between provinces and cities are dramatic. Table 1 indicates that the efficiency values of 15 provinces are under average levels, which accounts for 50 per cent of these values. Furthermore, the initial efficiency values for five provinces and cities reach 1 , which demonstrates that the allocation for these five provinces and cities is DEA effective but that the other 25 provinces and cities are not DEA efficient. Some provinces, such as Shan Xi and Ning Xia, do not perform well in terms of efficiency. For provinces with abundant energy resources, such as Shan $\mathrm{X} i$, a low efficiency value means that there is greater potential to reduce carbon emissions.

Based on the original DEA model, we may adjust the emission rights of all provinces and cities based on their efficiency values and slack variables so that the lowest carbon emission with respect to the economy and the carbon dioxide emission with the greatest efficiency might be achieved. However, this adjustment does not consider specific allocation situations, which is not feasible. For example, the total amount of carbon dioxide emission is fixed, which means that when one DMU reduces the input of a variable, the input of this variable into another DMU will increase accordingly. The efficiency values of original DEA and slack variables are not consistent with restraining the fixed total amount and are not able to achieve reasonable reallocation of input. Therefore, we must assess the efficiency values of the ZSG-DEA model and make proper adjustments of carbon emission rights based on the efficiency values and slack variables of the ZSG-DEA model.

Fair and effective allocation results in effective allocative efficiencies for all participating provinces, whether in the original DEA model or in the ZSG-DEA model. As discussed above, the status quo of most provinces and cities is currently ineffective, and for that reason we must adjust the ZSG-DEA model. Based on Equation (2), the amount that carbon emission must be reduced in some areas and the amount of increase needed in other provinces and cities can be calculated to reach the efficient frontiers. The multiple iteration method is employed to allow all provinces and cities reach their efficient frontiers.

According to the results of the ZSG-DEA model in the initial allocation, we obtain the voluntary trade matrix for all provinces and cities, and the results of the adjusted allocation are shown in Tables Tables A1-A5. Using the adjusted emission amount as the input variable and making another estimation of the efficiency values of the original DEA model, we find that the original DEA efficiency values increase significantly. 
Table 1. Predicted statistics and efficiency values in 2020 by taking 2010 as the benchmark. Data envelopment analysis: DEA.

\begin{tabular}{|c|c|c|c|c|c|c|}
\hline Region & GDP * & POP ** & TEC *** & $\mathrm{CDE} * * * *$ & NFEC ***** & Initial DEA Efficiency \\
\hline Beijing & $26,877.87$ & 2068.83 & $22,419.36$ & 9139.91 & 1367.02 & 1.000 \\
\hline Tianjin & $18,004.03$ & 1485.04 & $20,914.45$ & 9121.63 & 2889.98 & 0.709 \\
\hline Hebei & $36,199.64$ & 7656.45 & $96,631.92$ & $44,090.88$ & $10,385.22$ & 0.519 \\
\hline Shanxi & $12,449.74$ & 3716.95 & $65,261.87$ & $39,113.35$ & $10,956.98$ & 0.250 \\
\hline Inner Mongolia & $25,285.27$ & 2614.88 & $80,577.81$ & $26,620.04$ & $12,531.91$ & 0.467 \\
\hline Liaoning & $35,699.68$ & 4689.23 & $82,569.12$ & $36,992.38$ & 6424.49 & 0.554 \\
\hline Jilin & $18,129.91$ & 2944.26 & $29,774.55$ & $13,487.87$ & 3248.63 & 0.628 \\
\hline Heilongjiang & $15,782.96$ & 4091.55 & $40,554.55$ & $18,324.52$ & 3825.59 & 0.730 \\
\hline Shanghai & $30,934.54$ & 2170.85 & $33,221.39$ & $16,012.34$ & 4896.33 & 0.683 \\
\hline Jiangsu & $80,671.03$ & 8447.49 & $90,921.19$ & 35754.88 & $17,178.75$ & 0.800 \\
\hline Zhejiang & $47,522.26$ & 5760.86 & $64,437.20$ & $23,966.21$ & $11,986.14$ & 0.732 \\
\hline Anhui & $25,379.27$ & 6557.59 & $47,523.72$ & $15,409.76$ & 7412.07 & 0.793 \\
\hline Fujian & $30,288.19$ & 3945.73 & $36,315.67$ & $10,800.30$ & 7006.64 & 1.000 \\
\hline Jiangxi & $17,176.17$ & 4828.64 & $19,895.95$ & 8897.53 & 3316.20 & 1.000 \\
\hline Shandong & $75,516.20$ & $10,288.25$ & $142,845.79$ & $55,889.96$ & $15,926.08$ & 0.559 \\
\hline Henan & $41,507.36$ & $10,215.61$ & $73,841.23$ & $33,116.81$ & $11,424.78$ & 0.635 \\
\hline Hubei & $33,409.65$ & 6117.83 & $43,513.36$ & $18,272.22$ & $10,483.98$ & 0.728 \\
\hline Hunan & $32,288.39$ & 6904.05 & $36,930.61$ & $16,870.52$ & 5738.38 & 0.872 \\
\hline Guangdong & $82,065.21$ & $10,649.49$ & $82,889.85$ & $31,925.15$ & $14,533.07$ & 0.933 \\
\hline Guangxi & $17,782.83$ & 5342.28 & $21,211.93$ & 8176.29 & 5369.34 & 1.000 \\
\hline Hainan & 3738.86 & 951.63 & $19,054.95$ & 2322.30 & 717.30 & 1.000 \\
\hline Chongqing & $15,993.10$ & 3101.11 & $23,959.36$ & 7601.55 & 2562.52 & 0.936 \\
\hline Sichuan & $34,233.93$ & 8723.45 & $54,657.75$ & $17,616.22$ & 8862.26 & 0.904 \\
\hline Guizhou & 8790.90 & 4109.35 & $28,160.29$ & $13,197.12$ & 6845.51 & 0.544 \\
\hline Yunnan & $13,257.43$ & 4976.77 & $29,012.71$ & $13,031.79$ & 7063.82 & 0.646 \\
\hline Shanxi & $19,403.74$ & 4068.94 & $43,617.41$ & $15,249.49$ & 4979.50 & 0.618 \\
\hline Gansu & 6970.92 & 2847.05 & $21,029.52$ & 9459.62 & 4438.93 & 0.547 \\
\hline Qinghai & 2169.99 & 606.41 & 6678.64 & 2178.34 & 2453.37 & 0.537 \\
\hline Ningxia & 3284.43 & 691.15 & $15,651.77$ & 5856.23 & 2941.96 & 0.336 \\
\hline Xinjiang & 7614.99 & 2428.29 & $32,695.00$ & $12,639.81$ & 3248.63 & 0.533 \\
\hline Total & $818,427.83$ & $143,000.00$ & $1,406,769.35$ & $571,135.03$ & $211,015.40$ & $0.731^{* * * * * *}$ \\
\hline
\end{tabular}

* Unit: 100 million Chinese Yuan; ${ }^{* *}$ Population (unit: 10 thousand Chinese Yuan); ${ }^{* *}$ Total energy consumption (unit: 10 thousand tce, where tce is tons of standard coal, the unified standard unit of heat value); $* * * * \mathrm{CO}_{2}$ emissions (unit: 10 thousand t.c., where t.c. is tons of carbon, the standard unit of $\mathrm{CO}_{2}$ emissions); ${ }^{* * * * *}$ Non-fossil energy consumption (unit: 10 thousand tce); ${ }^{* * * * * *}$ It is the average initial distribution efficiencyof provinces and cities.

Given the initially allocated carbon dioxide emissions, consumption of NFFs (Non-fossil fuels) and the results of the ZSG-DEA model, we can obtain the increase and decrease matrix for the carbon allocations of all provinces and cities and can identify how to adjust the values to acquire a new set of adjusted carbon emission and NFF consumption, as shown by the first iteration in Table A1.

In the next step, the adjusted carbon emission and the consumption of NFFs are used as input variables to calculate the efficiency values of the original DEA model. The average efficiency value of the original DEA model is shown to increase to 0.894 , and the efficiency for all provinces and cities has improved significantly from their original state. Compared with the original $\mathrm{CO}_{2}$ emissions, the $\mathrm{CO}_{2}$ emissions in Hebei, Shanxi, Inner Mongolia, Liaoning, Jilin, Heilongjiang, Shandong, Henan, Guizhou, Gansu, Qinghai, Ningxia and Xinjiang have all been reduced, in a total amount of 631,691,800 tons of carbon (t.c.). Meanwhile, another 11 provinces and cities, including Beijing, Tianjin, Shanghai, Jiangsu, Zhejiang and Anhui, have accordingly increased their $\mathrm{CO}_{2}$ emissions by an overall volume of $631,691,800$ t.c. The sum of the increased and reduced amounts is zero, guaranteeing the precondition of the fixed total amount. As for another input factor-energy consumption of NFFs-10 provinces and cities, including Tianjin, Hebei, Shanxi and Inner Mongolia, have also reduced their input amount by 158,109,600 t.c.; meanwhile, another 12 provinces and cities, such as Beijing, Liaoning, Jilin and Heilongiiang, have increased their input amount by 158,109,600 t.c., thereby assuring the precondition of fixed total energy consumption. Although the efficiency values of all the provinces and cities have increased following the first iteration, they remain under fair carbon emission allowances. 
Therefore, another iterative calculation is necessary. After the second iterative adjustment, the average value of the initial DEA efficiency has reached 0.962 , with most provinces and cities close to 1 . In comparison with the first adjustment, 10 provinces and cities, such as Hebei, Shanxi, Inner Mongolia and Liaoning, continue to reduce their $\mathrm{CO}_{2}$ emissions, whereas another 12 provinces and cities, including Beijing, Tianjin, Shanghai, and Jiangsu, continue to increase their emissions. In terms of NFF consumption, 10 provinces and cities, such as Tianjin, Shanxi and Inner Mongolia, further reduce their consumption, whereas 14 provinces and cities, such as Beijing, Hebei and Liaoning, must increase their consumption accordingly.

Further adjustments are necessary as a fair and effective carbon emission allocation has not been achieved. After the third iteration, the initial DEA efficiency value reaches 0.991 , and almost all the allocative efficiency values nearly reach 0.99 . However, further adjustments are undertaken to achieve the most effective efficiency value as expected. The fourth iteration shows that the vast majority of provinces and cities have achieved fair and effective initial efficiency values (reached at 1), apart from a few provinces such as Jiangsu, Fujian, Hubei, Hunan, Guangdong etc. Therefore, a fifth iteration was carried out, as shown in Table 2, Table A5 and Figure 1.

After the fifth iteration, the DEA efficiency values of all 30 provinces and cities have become 1 . Comparing the initial allocation with the allocation after the fifth iteration, provinces such as Hebei, Shanxi, Inner Mongolia, Liaoning, Jilin, Heilongjiang, Shandong, Henan, Guizhou, Shaanxi, Gansu, Qinghai, Ningxia and Xinjiang all must reduce their carbon emissions, whereas the remaining provinces must increase their carbon emissions; Guangxi, Hainan, etc. demonstrate the most significant increases. Guangxi's carbon emission increases from $81,762,900$ t.c. to $160,709,800$ t.c., as shown in Tables 1, 3 and A5.

Table 2. Predicted efficiency values in 2020 using 2010 as a benchmark and taking five iterations.

\begin{tabular}{|c|c|c|c|c|c|c|}
\hline Region & $\begin{array}{c}\text { Initial DEA } \\
\text { Efficiency }\end{array}$ & $\begin{array}{l}\text { DEA Efficiency } \\
\text { Value of the } \\
\text { First Iteration }\end{array}$ & $\begin{array}{l}\text { DEA Efficiency } \\
\text { Value of the } \\
\text { Second Iteration }\end{array}$ & $\begin{array}{l}\text { DEA Efficiency } \\
\text { Value of the } \\
\text { Third Iteration }\end{array}$ & $\begin{array}{l}\text { DEA Efficiency } \\
\text { Value of the } \\
\text { Fourth Iteration }\end{array}$ & $\begin{array}{l}\text { DEA Efficiency } \\
\text { Value of the } \\
\text { Fifth Iteration }\end{array}$ \\
\hline Beijing & 1 & 1 & 1 & 1 & 1 & 1 \\
\hline Tianjin & 0.709 & 0.906 & 0.975 & 0.998 & 1 & 1 \\
\hline Hebei & 0.519 & 0.906 & 1 & 1 & 1 & 1 \\
\hline Shanxi & 0.25 & 0.567 & 0.95 & 0.993 & 1 & 1 \\
\hline $\begin{array}{c}\text { Inner } \\
\text { Mongolia }\end{array}$ & 0.467 & 0.791 & 0.952 & 0.997 & 1 & 1 \\
\hline Liaoning & 0.554 & 0.788 & 0.976 & 0.999 & 1 & 1 \\
\hline Jilin & 0.628 & 0.982 & 1 & 1 & 1 & 1 \\
\hline Heilongjiang & 0.73 & 0.893 & 0.963 & 0.987 & 1 & 1 \\
\hline Shanghai & 0.683 & 0.898 & 0.975 & 0.998 & 1 & 1 \\
\hline Jiangsu & 0.8 & 0.952 & 0.93 & 0.991 & 0.996 & 1 \\
\hline Zhejiang & 0.732 & 0.923 & 0.908 & 0.984 & 0.996 & 1 \\
\hline Anhui & 0.793 & 0.951 & 0.97 & 0.992 & 1 & 1 \\
\hline Fujian & 1 & 1 & 0.915 & 0.994 & 0.992 & 1 \\
\hline Jiangxi & 1 & 1 & 1 & 1 & 1 & 1 \\
\hline Shandong & 0.559 & 0.867 & 0.946 & 0.994 & 1 & 1 \\
\hline Henan & 0.635 & 0.883 & 0.95 & 0.992 & 1 & 1 \\
\hline Hubei & 0.728 & 0.927 & 0.904 & 0.951 & 0.991 & 1 \\
\hline Hunan & 0.872 & 0.966 & 0.96 & 0.981 & 0.997 & 1 \\
\hline Guangdong & 0.933 & 0.989 & 0.948 & 1 & 0.992 & 1 \\
\hline Guangxi & 1 & 1 & 1 & 1 & 1 & 1 \\
\hline Hainan & 1 & 1 & 1 & 1 & 1 & 1 \\
\hline Chongqing & 0.936 & 0.987 & 0.931 & 0.962 & 0.991 & 1 \\
\hline Sichuan & 0.904 & 0.989 & 0.966 & 0.993 & 1 & 1 \\
\hline Guizhou & 0.544 & 0.831 & 0.986 & 0.993 & 1 & 1 \\
\hline Yunnan & 0.646 & 0.882 & 0.992 & 0.996 & 1 & 1 \\
\hline Shanxi & 0.618 & 0.814 & 0.89 & 0.975 & 0.998 & 1 \\
\hline Gansu & 0.547 & 0.823 & 0.984 & 0.992 & 1 & 1 \\
\hline Qinghai & 0.537 & 0.867 & 0.987 & 0.983 & 1 & 1 \\
\hline Ningxia & 0.336 & 0.658 & 0.945 & 0.991 & 1 & 1 \\
\hline Xinjiang & 0.533 & 0.773 & 0.97 & 0.984 & 1 & 1 \\
\hline
\end{tabular}




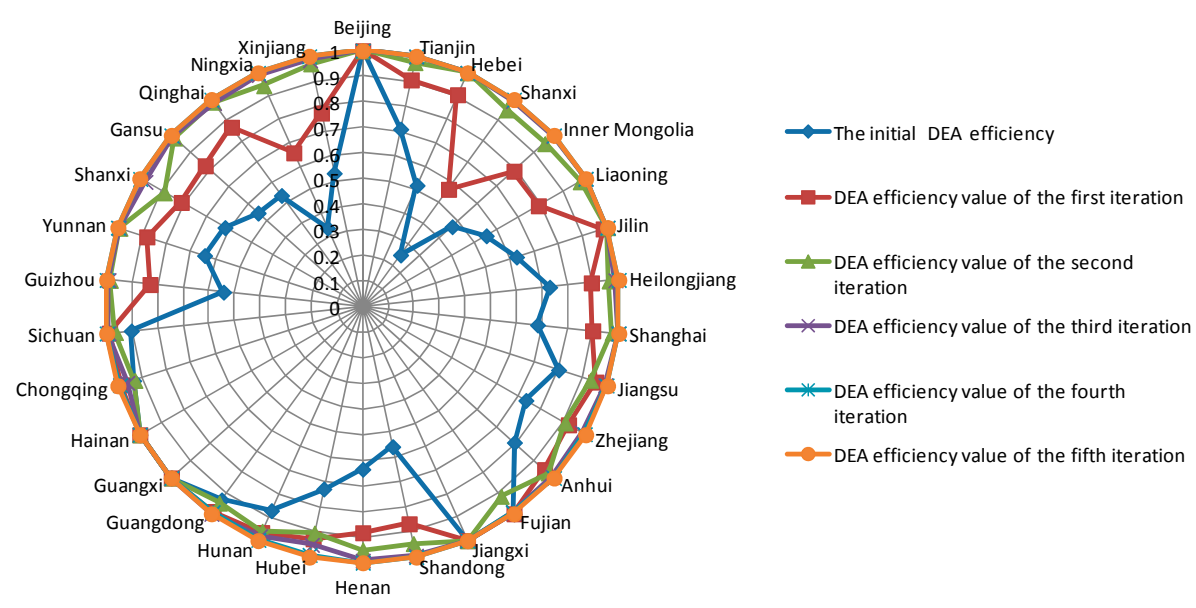

Figure 1. Predicted efficiency values in 2020 using 2010 as a benchmark and taking five iterations.

Table 3. Predicted $\mathrm{CO}_{2}$ emission allowance values in 2020 using 2010 as a benchmark.

\begin{tabular}{|c|c|c|c|c|c|c|}
\hline Region & $\mathrm{CO}_{2} * 0$ & $\mathrm{CO}_{2} * 1$ & $\mathrm{CO}_{2}{ }^{*}{ }^{2}$ & $\mathrm{CO}_{2} * 3$ & $\mathrm{CO}_{2} * 4$ & $\mathrm{CO}_{2} * 5$ \\
\hline Beijing & 9139.91 & $12,532.24$ & $13,979.17$ & $14,494.35$ & $14,804.3$ & $14,921.51$ \\
\hline Tianjin & 9121.63 & 9854.37 & $10,049.35$ & $10,327.37$ & $10,546.46$ & $10,629.96$ \\
\hline Hebei & $44,090.88$ & $30,763.29$ & $25,989.19$ & $26,463.97$ & $27,035.1$ & $27,248.99$ \\
\hline Shanxi & $39,113.35$ & $21,009.38$ & 14045.3 & $13,957.53$ & $14,168.89$ & $14,281.07$ \\
\hline Inner Mongolia & $26,620.04$ & $21,712.03$ & $19,495.64$ & $19,856.89$ & $20,280.97$ & $20,441.53$ \\
\hline Liaoning & $36,992.38$ & $27,870.89$ & $24,305.74$ & $24,769.18$ & $25,302.13$ & $25,502.38$ \\
\hline Jilin & $13,487.87$ & $10,915.47$ & 9558.3 & 9844.67 & 9920.65 & $10,000.1$ \\
\hline Heilongjiang & $18,324.52$ & $15,077.71$ & $13,442.03$ & $13,625.17$ & $13,732.4$ & $13,843.62$ \\
\hline Shanghai & $16,012.34$ & $16,807.32$ & $16,983.06$ & $17,458.65$ & $17,831.06$ & $17,972.23$ \\
\hline Jiangsu & $35,754.88$ & $42,785.85$ & $45,971.28$ & $46,879.16$ & $45,195.59$ & $45,101.71$ \\
\hline Zhejiang & $23,966.21$ & $27,337.58$ & $28,674.44$ & $28,819.88$ & $27,877.03$ & $27,138.91$ \\
\hline Anhui & $15,409.76$ & $18,907.47$ & $20,322.63$ & $20,603.08$ & $20,885.81$ & $21,055.4$ \\
\hline Fujian & $10,800.3$ & $16,007.48$ & $18,281.37$ & $16,481.85$ & $16,754.24$ & $16,743.07$ \\
\hline Jiangxi & 8897.53 & $12,199.89$ & $13,608.45$ & $14,109.97$ & $14,411.7$ & $14,525.79$ \\
\hline Shandong & $55,889.96$ & $50,029.84$ & $48,896.29$ & $49,261.04$ & $50,107.18$ & $48,333.68$ \\
\hline Henan & $33,116.81$ & $32,678.81$ & $32,513.92$ & $32,460.95$ & $32,525.46$ & $32,782.57$ \\
\hline Hubei & $18,272.22$ & $21,436.2$ & $22,680.89$ & $21,039.75$ & $20,166.37$ & $20,136.15$ \\
\hline Hunan & $16,870.52$ & $21,128.66$ & $22,880.2$ & $24,120.19$ & $21,824.64$ & $21,919.79$ \\
\hline Guangdong & $31,925.15$ & $43,772.33$ & $48,825.56$ & $44,301.63$ & $45,404.14$ & $45,344.96$ \\
\hline Guangxi & 8176.29 & $12,902.9$ & 15001.14 & 15610.38 & $15,944.75$ & $16,070.98$ \\
\hline Hainan & 2322.3 & 3184.24 & 3551.88 & 3682.78 & 3761.54 & 3791.32 \\
\hline Chongqing & 7601.55 & $10,128.85$ & 11192.65 & 10785.09 & $10,079.15$ & $10,068.19$ \\
\hline Sichuan & $17,616.22$ & $24,003.86$ & 26723.52 & 27118.66 & $27,241.4$ & $27,454.56$ \\
\hline Guizhou & $13,197.12$ & $12,769.24$ & 12394.14 & 12797.92 & $12,985.58$ & $13,089.43$ \\
\hline Yunnan & $13,031.79$ & $14,244.31$ & 14625.61 & 15140.85 & $15,399.52$ & $15,522.51$ \\
\hline Shanxi & $15,249.49$ & $16,103.73$ & 14914.46 & 14314.12 & $13,896.83$ & $13,979.34$ \\
\hline Gansu & 9459.62 & 9041.52 & 8694.33 & 8973.79 & 9094.69 & 9167.05 \\
\hline Qinghai & 2178.34 & 1974.81 & 1974.75 & 2065.16 & 2078.78 & 2094.95 \\
\hline Ningxia & 5856.23 & 4101.65 & 3162.34 & 3126.23 & 3188.3 & 3213.47 \\
\hline Xinjiang & $12,639.81$ & 9853.11 & 8397.38 & 8644.7 & 8690.36 & 8759.82 \\
\hline
\end{tabular}

${ }^{*} \mathrm{CO}_{2}$ emission in units of 10 thousand t.c. (tons of carbon, the standard unit of carbon dioxide emissions); 0: The predicted $\mathrm{CO}_{2}$ emission allowance in 2020 using 2010 as a benchmark and taking no iterations; 1 : The predicted $\mathrm{CO}_{2}$ emission allowance in 2020 using 2010 as a benchmarkand taking the 1st iteration; 2: The predicted $\mathrm{CO}_{2}$ emission allowance in 2020 using 2010 as a benchmarkand taking the 2nd iteration; 3: The predicted $\mathrm{CO}_{2}$ emission allowance in 2020 using 2010 as a benchmarkand taking the 3rd iteration; 4: The predicted $\mathrm{CO}_{2}$ emission allowance in 2020 using 2010 as a benchmarkand taking the 4th iteration; 5: The predicted $\mathrm{CO}_{2}$ emission allowance in 2020 using 2010 as a benchmarkand taking the 5th iteration. 
For non-fossil energy consumption, Tianjin, Hebei, Shanxi, Inner Mongolia, Shanghai, Jiangsu, Zhejiang, Fujian, Shandong, Hubei, Guizhou, Gansu, Qinghai and Ningxia must reduce their consumption, and the rest of the provinces must increase their consumption; Beijing must increase most. The consumption assigned after five iterations is 1.18 times that of the initial allocation.

Next, we compare our results with past work. Miao et al. [23] researched $\mathrm{CO}_{2}$ emissions allowances among provinces in 2010 in China but did not research $\mathrm{CO}_{2}$ emissions allowances among provinces in 2020 in China. References [24-36] did not use the ZSG-DEA model and/or did not research the $\mathrm{CO}_{2}$ emissions allowance among provinces in China.

Wang et al. [22] researched $\mathrm{CO}_{2}$ emission allowances among provinces in 2020 in China using the ZSG-DEA model. Thus, our results are most comparable with Wang et al. [22], and the $\mathrm{CO}_{2}$ emissions difference values after the 5 th iteration in 2020 from both papers are illustrated in Figure 2. Although not all the input and output variables used in Wang et al. [22] are the same as those used in this paper, both papers reveal similar trends in $\mathrm{CO}_{2}$ emissions difference values for 2020 after the 5th iteration. However, in this paper, the $\mathrm{CO}_{2}$ emissions difference value in most provinces and cities after the 5th iteration in 2020 is smaller than that in Wang et al. [22]. We investigate the reasons for this difference.
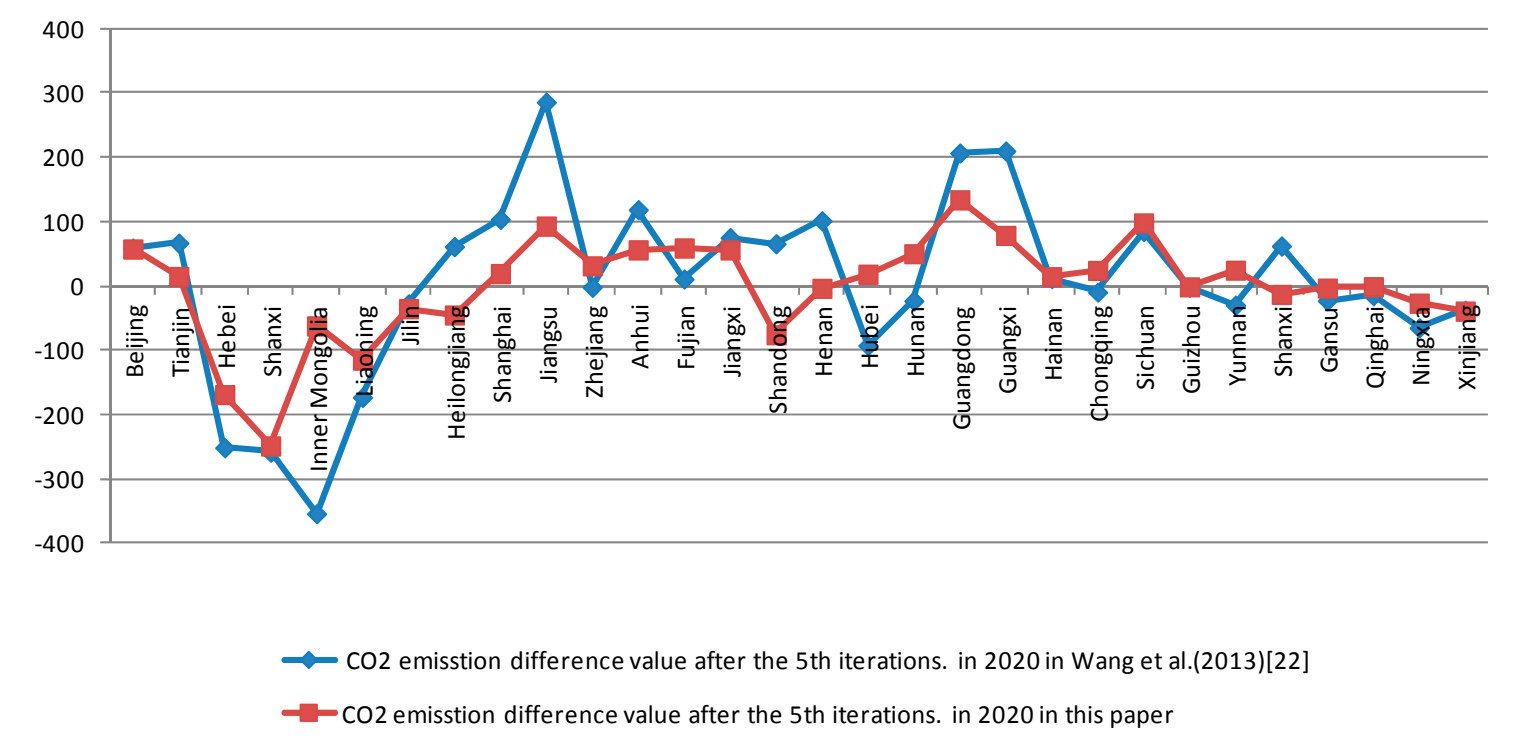

Figure 2. The trend of $\mathrm{CO}_{2}$ emission difference values after the 5 th iteration in 2020 between this paper and Wang et al. [22].

We believe that the main reason for this difference is that the input and output variables in Wang et al. [22] and this paper are not all the same. The input variables used in Wang et al. [22] are total energy consumption, $\mathrm{CO}_{2}$ emissions and non-fossil energy consumption. All three inputs in Wang et al. [22] have constant total amounts that must be reallocated among China's regions. The output variables used in Wang et al. [22] are GDP (based on 2005 prices) and POP. Our article uses $\mathrm{CO}_{2}$ emissions and non-fossil energy consumption as input variables; we do not use total energy consumption because we posit that this variable is changeable. The output variables used in our article are total energy consumption, gross domestic product (based on 2010 prices) and POP.

\section{Methodology}

\subsection{BBC-DEA Model}

It is presumed that each assessment system has a number $(n)$ of the same types of DMUs and that each unit has a number $(r)$ input indexes and a number $(m)$ of output indexes. The equation for the BBC-DEA model of the relative efficiency assessment of $\mathrm{DMU}_{0}$ is set forth as Equation (1), in which $\theta_{0}$ 
represents the relative efficiency of $\mathrm{DMU}_{0}$, while $\lambda_{i}$ indicates the ratio of each $\mathrm{DMU}_{i}$ in a restructured and effectively combined decision unit relative to $\mathrm{DMU}_{0}$ :

$$
\begin{gathered}
\min \theta_{\mathrm{o}} \\
\text { s.t. } \sum_{i=1}^{n} \lambda_{i} y_{i j} \geqslant y_{o j}, j=1,2,3, \ldots, m \\
\sum_{i=1}^{n} \lambda_{i} x_{i k} \leqslant \theta_{\mathrm{o}} x_{\mathrm{o} k}, k=1,2,3, \ldots r \\
\sum_{i=1}^{n} \lambda_{i}=1, i=1,2,3, \ldots n \\
\lambda_{i} \geqslant 0, i=1,2,3, \ldots n
\end{gathered}
$$

The input and output variables of the classic DEA model (CCR, BBC, etc.) are relatively independent. Given any of the DMUs, its input or output will not affect any other DMU's input or output variables. A classic DEA model only demonstrates the relative efficiency of the original state. However, under the condition of competition, the amount of input or output for variables should be restricted for the constant total, and the input and output of each DMU are related to one another to ensure this constant. If one of the inefficient DMUs increases its input or output to achieve a greater efficiency frontier, other DMUs must reduce their input or output, which strays from the assumptions of the classic DEA model. This characteristic conforms exactly to the feature of a ZSG, which requires that the loss or earnings of a stakeholder be the earnings or loss of other stakeholders to ensure that the total earning amount is zero.

\subsection{Zero Sum Earning DEA Model}

The initial ZSG-DEA model was proposed by Gomes and Lins [37] on the basis of an input-oriented CCR-DEA model. To realize an effective DEA model, $\mathrm{DMU}_{0}$ must reduce the amount of input $k$ as $u_{0}=x_{0 k}\left(1-\varphi_{0}\right)$ and allocate this amount proportionally to other DMUs. Thus, the input allocation value acquired by the $i^{\text {th }} \mathrm{DMU}$ is $x_{i k} / \Sigma x_{i k} \cdot x_{0 k}\left(1-\varphi_{0}\right)$. As all the DMUs experience a certain increase or decrease of input proportion simultaneously, the reallocation of input $k$ after adjustment is:

$$
x_{i k}^{\prime}=\sum_{o \neq i}\left[\frac{x_{i k}}{\sum_{i \neq 0} x_{i k}} \cdot x_{o k}\left(1-\varphi_{o}\right)\right]-x_{i k}\left(1-\varphi_{i}\right), i=1,2,3, \ldots n
$$

In this study, it is assumed that more inputs have fixed total amounts. When a DMU aims for increased efficiency, different proportions of increase or decrease of a fixed total amount follow. Meanwhile, it is believed that fixed earnings are effective at setting a scope, such that when a DMU operates within an optimum scope, the application of the variable's earnings become more reasonable. In addition, because each DMU in this study, whether big or small or in different developing phases, can be distinguished from one other, our assumption is that not all the DMUs operate within the optimum scope:

$$
\begin{gathered}
E_{\mathrm{ZSG}}=\min \sum_{i=1}^{m} w_{i} \theta_{i} \\
\text { s.t. } \sum_{j=1}^{n} \lambda_{j} y_{r j} \geqslant y_{r k}, r=1 \ldots . . \\
\sum_{j=1}^{n} \lambda_{j} x_{i j}\left(1+\frac{x_{i k}\left(1-\theta_{i}\right)}{\sum_{j=1, j \neq k}^{n} x_{i j}}\right) \leqslant \theta_{i} x_{i k}, i=1 \ldots . m \\
\sum_{i=1}^{m} w_{i}=1, w_{i} \geqslant 0, i=1 \ldots . m \\
\lambda_{j} \geqslant 0, j=1 \ldots . n
\end{gathered}
$$

where $\theta_{i}$ is the measurement of the efficiency of ZSG-DEA related to the number $(i)$ of DMUs in Equation (3), when all $i$ inputs are limited under fixed conditions; $w_{i}$ is the weight of $\theta_{i}$; $\mathrm{E}_{\mathrm{ZSG}}$ is the 
efficiency of the average value of the uniform weight of each DMU; $x_{i j}$ and $y_{r j}$ are the input and output values, respectively; $x_{i k}$ and $y_{r k}$ refer to the input and output values, respectively, of the DMU in their assessment; and $\lambda_{i}$ is the contribution rate of effective planning made by each DMU.

\subsection{A Zero Sum Gains Data Envelopment Analysis Model for $\mathrm{CO}_{2}$ Allowance Allocation in China}

To reflect the demographic and economic characteristics of each region in the process of allowance allocation, the output variables used in the optimized ZSG-DEA model are GDP, POP and energy consumption in 2010. The input variables are $\mathrm{CO}_{2}$ emission and consumption of non-fossil fuels (NFFs). These two inputs have a fixed total amount and must be reallocated among provinces. The ZSG-DEA model for China is as follows:

$$
\begin{gathered}
E_{\mathrm{ZSG}}^{\prime}=\min ^{\mathrm{co} 2} \theta^{\mathrm{co} 2}+w^{\mathrm{NF}} \theta^{\mathrm{NF}} \\
\text { s.t. } \sum_{j=1}^{n} \lambda_{j} y_{j}^{\mathrm{GDP}} \geqslant y_{k}^{\mathrm{GDP}} \\
\sum_{j=1}^{n} \lambda_{j} y_{j}^{\mathrm{POP}} \geqslant y_{k}^{\mathrm{POP}} \\
\sum_{j=1}^{n} \lambda_{i} y_{j}^{\mathrm{TE}} \geqslant y_{j}^{\mathrm{TE}} \\
\sum_{j=1}^{n} \lambda_{j} x_{j}^{\mathrm{co} 2}\left(1+\frac{x_{k}^{\mathrm{co} 2}\left(1-\theta^{\mathrm{co} 2}\right)}{\sum_{j=1, j \neq k}^{n} x_{j}^{\mathrm{co} 2}} \leqslant \theta^{\mathrm{co} 2} x_{k}^{\mathrm{co} 2}\right. \\
\sum_{j=1}^{n} \lambda_{j} x_{j}^{\mathrm{NF}}\left(1+\frac{x_{k}^{\mathrm{NF}}\left(1-\theta^{\mathrm{NF}}\right)}{\sum_{j=1, j \neq k}^{n} x_{j}^{\mathrm{NF}}}\right) \leqslant \theta^{\mathrm{NF}} x_{k}^{\mathrm{NF}} \\
w^{\mathrm{co} 2}+w^{\mathrm{NF}}=1, w^{\mathrm{CO} 2}>0 ; w^{\mathrm{NF}}>0 \\
\lambda_{i} \geqslant 0, j=1 \ldots . n
\end{gathered}
$$

where $\theta^{\mathrm{CO} 2}$ and $\theta^{\mathrm{NFF}}$ represent the efficiency of the $\mathrm{CO}_{2}$ emission allocation and that of NFF consumption, respectively. Likewise, $w^{\mathrm{CO} 2}$ and $w^{\mathrm{NFF}}$ are the weights of the two aforementioned efficiencies, respectively. We set the weight to $1 / 2$, as both efficiencies are regarded as equally important. Equation (4) is the specific application of Equation (3) to the allocative efficiency of carbon emission reduction at the provincial level in 2020 in China.

Equation (4) indicates that when various regions have the same level of carbon emission and NFF energy consumption, the region with the smaller POP and GDP has relatively low efficiency; when different regions have the same level of carbon emission and NFF energy consumption, the region with the larger POP and GDP has greater efficiency.

The transmission mechanism is described as follows. At first, all regions are not at the new ZSG-DEA frontier in China due to erroneous $\mathrm{CO}_{2}$ emission allocations among different regions in China. Then, all the regions draw close to the new ZSG-DEA frontier because of a change in the amounts of $\mathrm{CO}_{2}$ emissions in different regions in China. Finally, all regions are at the new ZSG-DEA frontier in China due to a change in the amounts of $\mathrm{CO}_{2}$ emissions allocated to the different regions in China. The transmission mechanism is also depicted in Figure 3, where MN indicates the DEA frontier and EF indicates the ZSG-DEA frontier that is required to achieve an efficiency value of 1 by the fifth iteration.

Region $\mathrm{A}$ and region $\mathrm{B}$ are not on the EF. By changing the amounts of $\mathrm{CO}_{2}$ emissions allocated to different regions, they move onto the EF. The input variables used are carbon dioxide emissions and NFF consumption. The output variables used in the optimized ZSG-DEA model are GDP, POP and energy consumption, as shown in Figure 3. 


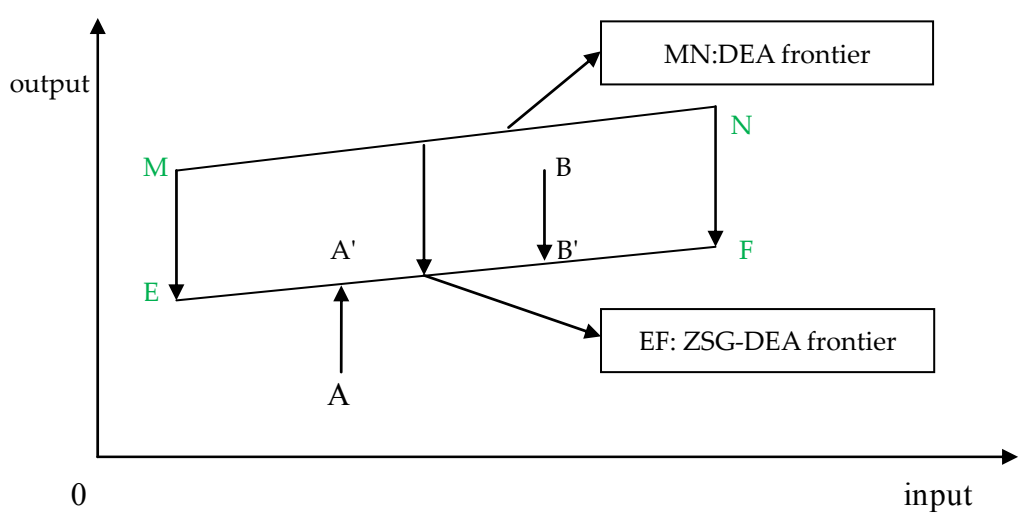

Figure 3. The transmission mechanism from the DEA frontier to the zero sum gains data envelopment analysis (ZSG-DEA) frontier.

\section{Data Sources and Processing}

This paper examines the carbon emission allowance allocation mode of all Chinese provinces in terms of efficiency. Therefore, the allocation allowance of all provinces must be first affirmed, and then the efficiency of the allocation mode may be examined. This study assumes that overall carbon emission in 2015 is $17 \%$ less than that in 2010, which is consistent with the goal of carbon emission reduction in the "12th Five Year Plan". At the Copenhagen United Nations Climate Change Conference, the Chinese government pledged that its carbon emission in 2020 would be reduced by $40 \%-45 \%$ from that its 2005 levels.

These results show that China's carbon emission reduction goal for 2020 will be approximately $31.3 \%$ if the 2010 value is taken as the benchmark. After affirming the total amount of the allocation, the carbon emissions allowance for each province can be simulated in terms of the optimum allocation of efficiency.

Using 2010 as the base year, the total amount of carbon emissions in 2020 and its allocation to each province and city can be estimated and predicted with optimal efficiency. The table below presents the carbon emissions, energy consumption, GDP, POP, etc., in all provinces and cities in 2010, which are used as the initial data (see Table 4).

The calculation of actual carbon emission in each province and city is derived from the amount of energy consumption in the energy balance sheets for all provinces and cities in the China Energy Statistical Yearbook 2011 [38-44]. The detailed calculation methods for carbon emission are described in the Guidelines for the Provincial Greenhouse Gas List [45], which is also called IPCC Method 1. According to this method, actual carbon emission is derived from the consumption of various fossil fuels, the heat per unit and carbon content per unit of various types of fuels plus the average oxidation rate of the main equipment used to burn various fuels, after deducting fixed carbon content and other parameters of fossil fuels used for non-energy purposes. However, it has been proven that it is difficult to acquire certain data in the calculation process, such as the number of products with fixed carbon content, etc. Therefore, an alternative method is employed in this study and is demonstrated below.

First, the energy consumption of different types of fossil fuels is converted into that of standard coal, and then the carbon emission factor, fixed carbon rate, oxidation rate of carbon and other parameters are used to calculate the emission amount of carbon and carbon dioxide in different types of fuels. The specific equation for the calculation is as follows:

$X_{i}=\Sigma$ production + import - export \pm increase or decrease of stock \pm others (mainly adding fuels overseas)

The emission amount of carbon $(P C)$ is as follows:

$$
P C=\sum_{i=1}^{n}\left[k_{i} \times\left(\lambda_{i} \varphi_{i}-\theta_{i}\right) \times X_{i}\right]
$$


where $k$ is the carbon oxidation rate; $\lambda$ is the conversion coefficient of standard coal; $\varphi$ is the potential carbon emission factors; and $\theta$ is the solid carbon rate.

Table 4. Data from 2010.

\begin{tabular}{|c|c|c|c|c|c|c|}
\hline Region & GDP * & POP ** & TEC *** & $\mathrm{CDE}^{* * * *}$ & NFEC $* * * * *$ & $\begin{array}{l}\text { The Initial DEA } \\
\text { Efficiency Value }\end{array}$ \\
\hline Beijing & 13,723 & 1755 & 9038.53 & 1535.05 & 323.23 & 1.000 \\
\hline Tianjin & 9720 & 1228 & $10,263.82$ & 7592.48 & 683.32 & 0.537 \\
\hline Hebei & 20,255 & 7034 & $49,853.14$ & $12,222.90$ & 2455.54 & 0.726 \\
\hline Shanxi & 8529 & 3427 & $53,262.19$ & 74321.14 & 2590.73 & 0.735 \\
\hline Inner Mongolia & 11,981 & 2422 & 7908.22 & $83,730.53$ & 2963.12 & 0.148 \\
\hline Liaoning & 18,263 & 4319 & $39,905.99$ & $13,182.51$ & 1519.04 & 0.939 \\
\hline Jilin & 8684 & 2740 & $13,802.69$ & 6438.69 & 768.13 & 0.656 \\
\hline Heilongjiang & 9950 & 3826 & $22,457.83$ & $16,860.45$ & 904.54 & 0.888 \\
\hline Shanghai & 17,959 & 1921 & $16,687.51$ & 2696.97 & 1157.72 & 0.849 \\
\hline Jiangsu & 40,516 & 7725 & $39,186.97$ & 6253.51 & 4061.85 & 0.730 \\
\hline Zhejiang & 27,154 & 5180 & $24,316.20$ & 3908.13 & 2834.07 & 0.701 \\
\hline Anhui & 12,120 & 6131 & $18,184.14$ & $13,618.62$ & 1752.55 & 0.625 \\
\hline Fujian & 14,369 & 3627 & $12,201.62$ & 4670.97 & 1656.69 & 0.393 \\
\hline Shanxi & 9433 & 4432 & $10,315.92$ & 1166.16 & 784.10 & 1.000 \\
\hline Shandong & 39,787 & 9470 & $63,189.12$ & $24,583.15$ & 3765.66 & 0.600 \\
\hline Henan & 22,619 & 9487 & $41,340.85$ & $23,572.29$ & 2701.34 & 0.640 \\
\hline Hubei & 15,638 & 5720 & $20,135.70$ & 1246.26 & 2478.89 & 1.000 \\
\hline Hunan & 15,245 & 6406 & $15,979.85$ & 7907.36 & 1356.82 & 0.837 \\
\hline Guangdong & 45,963 & 9638 & $33,264.81$ & 9290.76 & 3436.28 & 0.559 \\
\hline Guangxi & 8910 & 4856 & $10,620.27$ & 2321.48 & 1269.56 & 0.677 \\
\hline Hanan & 2105 & 859 & 2857.06 & 1364.91 & 169.60 & 0.909 \\
\hline Chongqing & 8562 & 2859 & 8595.60 & 5065.61 & 605.90 & 0.843 \\
\hline Sichuan & 16,745 & 8185 & $21,082.59$ & $11,349.42$ & 2095.45 & 0.694 \\
\hline Guzhou & 4421 & 3798 & $13,270.06$ & $15,446.41$ & 1618.59 & 0.422 \\
\hline Yunan & 7336 & 4571 & $13,435.03$ & 9687.58 & 1670.21 & 0.488 \\
\hline Shaanxi & 10,285 & 3772 & $16,946.43$ & $42,016.28$ & 1177.38 & 0.585 \\
\hline Gansu & 3810 & 2635 & 9488.83 & 5217.85 & 1049.57 & 0.452 \\
\hline Qinghai & 1250 & 557 & 2751.52 & 2850.40 & 580.09 & 0.176 \\
\hline Ningxia & 1610 & 625 & 8673.02 & 7039.19 & 695.61 & 0.446 \\
\hline Xinjiang & 4983 & 2159 & $15,049.29$ & $17,993.44$ & 768.13 & 0.701 \\
\hline Total & 431,925 & 131,364 & $624,064.79$ & $435,150.50$ & $49,893.71$ & \\
\hline
\end{tabular}

* Unit: 100 million Chinese Yuan; ${ }^{* *}$ Population (unit: 10 thousand Chinese Yuan); ${ }^{* * *}$ Total energy consumption (unit: 10 thousand tce, where tce is tons of standard coal, the unified standard unit of heat value); **** $\mathrm{CO}_{2}$ emissions (Unit: 10 thousand t.c., where t.c. is tons of carbon, the standard unit of $\mathrm{CO}_{2}$ emissions); ***** Non-fossil energy consumption (Unit: 10 thousand tce).

$X_{i}$ represents the total energy consumption in the $i^{\text {th }}$ province or city. The parameters of other models also can be found in Table 5 [46]. Because the molecular weight of $\mathrm{CO}_{2}$ is 44 and the molecular weight of carbon is 12 , the total carbon emission of each province calculated above can be converted into $\mathrm{CO}_{2}$ emission, based on this ratio. For the energy conversion, the conversion coefficient used in this study is 29,307.6 MJ of heat of standard coal per ton (see Table 5).

The data regarding NFFs are calculated on the basis of the Annual Development Report of China's Power Sector 2011 [47], issued by the China Electricity Council. NFFs refer to energy resources that are not coal, petroleum, natural gas or others; thus, NFFs consist of those resources that are not formed through long-term geological transformation that can only be consumed once and instead include current new energies and renewable energies such as nuclear energy, wind energy, solar energy, water energy, etc. According to the actual praxis and the available data, the hydroelectric and thermal energy data of NFFs are calculated for the consumption of non-fossil energy and converted into standard coal, derived from the conversion standard of 0.1229 standard coal/KW that is based on the national standard found in GB-2008 [48].

The data for GDP and the populations of provinces in 2010 are obtained from the China Statistical Yearbook 2011. According to the Energy Information Administration (EIA), the United States energy information administration website and the International Energy Outlook [49], the predicted average 
annual growth rate of GDP for China is $6.6 \%$ from 2010 to 2030, which is used in this study for projecting GDP in 2020. Moreover, China's population will reach 1.43 billion by 2020 in accordance with World Population Prospects [50], published by the United Nations Department of Economic and Social Affairs (UNDESA). The prediction of total energy consumption in 2020 is calculated using the energy/GDP elasticity coefficient. As for the energy consumption goal of NFFs, based on the medium- and long-term plans of national renewable energy development, non-fossil energies should account for $15 \%$ of primary energy consumption by 2020 . The consumption ratio of NFFs over primary energy equals the energy consumption of NFFs/the total consumption of primary energy (fossil fuels + consumption of NFFs). This calculation is used to predict the energy consumption of NFFs in 2020.

The total amount of national carbon dioxide emission in 2020 is predicted to be 5,711,350,300 t.c. Taking the carbon emission of all provinces and cities from 2010-2014 and the overall allowance into consideration, the predicted values of initial allowance allocation results and other variables are shown in Table 1.

Table 5. Model parameters.

\begin{tabular}{ccccc}
\hline Fuels & CCSC $(\lambda)^{*}$ & PCEF $(\varphi)^{* *}$ & SCR $(\theta) * * *$ & COR $(\boldsymbol{k}) * * *$ \\
\hline Raw coal & 0.7143 & 27.3 & 0.3 & 0.98 \\
Washed coal & 0.9 & 25.8 & 0.3 & 0.98 \\
Other washed coal & 0.5253 & 25.8 & 0.3 & 0.98 \\
Coking coal & 0.9714 & 29.5 & 0.3 & 0.98 \\
Crude oil & 1.4286 & 29.5 & 0.8 & 0.99 \\
Gasoline & 1.4714 & 18.9 & 0.8 & 0.99 \\
Kerosene & 1.4714 & 19.6 & 0.75 & 0.99 \\
Diesel & 1.4571 & 20.2 & 0.8 & 0.99 \\
Heavy oil & 1.4286 & 21.1 & 0.5 & 0.99 \\
Natural gas & 1.33 & 15.3 & 0.33 & 0.995 \\
Coke oven gas & 6.1417 & 29.5 & 0.3 & 0.995 \\
Other gas & 2.8758 & 29.5 & 0.3 & 0.995 \\
Refinery dry gas & 1.5714 & 20 & 0.5 & 0.995 \\
Type coal & 1.7143 & 17.2 & 0.8 & 0.99 \\
Liquefied petroleum gas (LPG) & 0.6068 & 25.8 & 0.3 & 0.98 \\
Other petroleum products & 1.3107 & 20 & 0.8 & 0.99 \\
Other coking products & 1.154 & 25.8 & 0.3 & 0.98 \\
\hline
\end{tabular}

* The conversion coefficient of standard coal $(\lambda) ;{ }^{* *}$ Potential carbon emission factors $(\varphi) ;{ }^{* * *}$ Solid carbon rate $(\theta) ;{ }^{* * * *}$ Carbon oxidation rate $(k)$.

\section{Conclusions}

From the perspective of allocative efficiency, carbon emission allowances for China's 30 provinces and cities are allocated in this study by employing a ZSG-DEA model. The carbon dioxide emissions index and non-fossil energy consumption index for 2020 are calculated by taking the emission reduction target in the "12th Five Year Plan" as the baseline. Then, the optimal allocation scheme for all provinces and cities in 2020 is achieved under fixed total volumes of carbon emissions and non-fossil energy consumption. As the largest country in the world in terms of overall carbon emission, China must reduce its carbon emissions to improve environmental quality. Therefore, it is important for China to set up carbon emission targets among provinces and cities during the next five years (the "13th Five Year Plan", which covers from 2016 to 2020), which would be more efficient and fair. We therefore suggest that provinces such as Hebei, Shanxi, Inner Mongolia, Liaoning, Jilin, Heilongjiang, Shandong, Henan, Guizhou, Shaanxi, Gansu, Qinghai, Ningxia and Xinjiang must reduce their carbon emissions. The rest of the provinces remain unchanged or reduce their carbon emissions although the rest of the provinces will increase their carbon emissions when applying zero sum gains analysis, with Guangxi and Hainan having the most significant increases, as reflected in Table 3. For non-fossil energy consumption, Tianjin, Hebei, Shanxi, Inner Mongolia, Shanghai, Jiangsu, Zhejiang, Fujian, Shandong, Hubei, Guizhou, Gansu, Qinghai and Ningxia must reduce consumption, 
and the remaining provinces must increase consumption, with Beijing needing to increase consumption the most.

Acknowledgments: The authors acknowledge valuable comments and suggestions from our colleagues. The authors are grateful to anonymous reviewers whose comments have helped to improve the manuscript. The research is funded jointly by the National Natural Science Foundation of China (71473010; 71573186); the Chinese philosophy \& social science research program (11 \& ZD140; 12BJY060); National Bureau of Statistics research project (2014LY113); the Beijing education committee fund, Beijing modern manufacturing base of Beijing philosophy and social sciences and the scientific research fund of economic and management school in the Beijing University of Technology (2016-2017); and the Specialized Research Fund of Higher Education in China (20131103110004).

Author Contributions: Shihong Zeng and Yan $\mathrm{Xu}$ conceived of, designed and performed the experiments; Shihong Zeng, Yan Xu, Jiuying Chen, Liming Wang, Qirong Li analyzed the data and contributed materials; all authors wrote the paper.

Conflicts of Interest: The authors declare no conflict of interest.

\section{Appendix A}

Table A1. Multiple iterations of data and DEA efficiency values of the first iteration.

\begin{tabular}{|c|c|c|c|}
\hline Province & $\mathrm{CO}_{2}{ }^{*}\left(10\right.$ Thousand t.c. $\left.{ }^{* *}\right)$ & NFF *** $\left(10\right.$ Thousand tce $\left.{ }^{* * * *}\right)$ & DEA Efficiency Value \\
\hline Beijing & $12,532.24$ & 2119.32 & 1.000 \\
\hline Tianjin & 9854.37 & 2676.44 & 0.906 \\
\hline Hebei & $30,763.29$ & 9312.45 & 0.906 \\
\hline Shanxi & $21,009.38$ & 8344.09 & 0.567 \\
\hline Inner Mongolia & $21,712.03$ & 9564.39 & 0.791 \\
\hline Liaoning & $27,870.89$ & 7007.52 & 0.788 \\
\hline Jilin & $10,915.47$ & 3866.11 & 0.982 \\
\hline Heilongjiang & $15,077.71$ & 4994.13 & 0.893 \\
\hline Shanghai & $16,807.32$ & 4440.14 & 0.898 \\
\hline Jiangsu & $42,785.85$ & $14,348.55$ & 0.952 \\
\hline Zhejiang & $27,337.58$ & $10,088.93$ & 0.923 \\
\hline Anhui & $18,907.47$ & 8556.65 & 0.951 \\
\hline Fujian & $16,007.48$ & 6409.96 & 1.000 \\
\hline Jiangxi & $12,199.89$ & 5141.15 & 1.000 \\
\hline Shandong & $50,029.84$ & $15,332.91$ & 0.867 \\
\hline Henan & $32,678.81$ & $13,164.68$ & 0.883 \\
\hline Hubei & $21,436.20$ & 9654.66 & 0.927 \\
\hline Hunan & $21,128.66$ & 7863.01 & 0.966 \\
\hline Guangdong & $43,772.33$ & $14,682.08$ & 0.989 \\
\hline Guangxi & $12,902.90$ & 6579.39 & 1.000 \\
\hline Hainan & 3184.24 & 1112.04 & 1.000 \\
\hline Chongqing & $10,128.85$ & 3554.47 & 0.987 \\
\hline Sichuan & $24,003.86$ & $10,807.61$ & 0.989 \\
\hline Guizhou & $12,769.24$ & 6503.37 & 0.831 \\
\hline Yunnan & $14,244.31$ & 7216.05 & 0.882 \\
\hline Shaanxi & $16,103.73$ & 5712.56 & 0.814 \\
\hline Gansu & 9041.52 & 4384.72 & 0.823 \\
\hline Qinghai & 1974.81 & 1870.26 & 0.867 \\
\hline Ningxia & 4101.65 & 2179.96 & 0.658 \\
\hline Xinjiang & 9853.11 & 3527.80 & 0.773 \\
\hline
\end{tabular}

${ }^{*} \mathrm{CO}_{2}$ emission; ${ }^{* *}$ t.c., tons of carbon (the standard unit of $\mathrm{CO}_{2}$ emission); ${ }^{* * *}$ non-fossil fuel; ${ }^{* * * *}$ tce, tons of standard coal (the unified standard unit of heat value). 
Table A2. Multiple iterations of data and DEA efficiency values of the second iteration.

\begin{tabular}{|c|c|c|c|}
\hline Province & $\mathrm{CO}_{2}{ }^{*}\left(10\right.$ Thousand t.c. $\left.{ }^{* *}\right)$ & NFF $* * *\left(10\right.$ Thousand tce $\left.{ }^{* * * *}\right)$ & DEA Efficiency Value \\
\hline Beijing & $13,979.17$ & 2694.60 & 1.000 \\
\hline Tianjin & $10,049.35$ & 2436.27 & 0.975 \\
\hline Hebei & $25,989.19$ & 9345.60 & 1.000 \\
\hline Shanxi & $14,045.30$ & 6381.48 & 0.950 \\
\hline Inner Mongolia & $19,495.64$ & 7425.92 & 0.952 \\
\hline Liaoning & $24,305.74$ & 7373.26 & 0.976 \\
\hline Jilin & 9558.30 & 4287.97 & 1.000 \\
\hline Heilongjiang & $13,442.03$ & 5848.76 & 0.963 \\
\hline Shanghai & $16,983.06$ & 3990.04 & 0.975 \\
\hline Jiangsu & $45,971.28$ & $12,411.58$ & 0.930 \\
\hline Zhejiang & $28,674.44$ & 8704.35 & 0.908 \\
\hline Anhui & $20,322.63$ & 9362.81 & 0.970 \\
\hline Fujian & $18,281.37$ & 5859.27 & 0.915 \\
\hline Jiangxi & $13,608.45$ & 6536.71 & 1.000 \\
\hline Shandong & $48,896.29$ & $15,122.64$ & 0.946 \\
\hline Henan & $32,513.92$ & $14,476.35$ & 0.950 \\
\hline Hubei & $22,680.89$ & 9002.52 & 0.904 \\
\hline Hunan & $22,880.20$ & 9452.04 & 0.960 \\
\hline Guangdong & $48,825.56$ & $14,925.97$ & 0.948 \\
\hline Guangxi & $15,001.14$ & 7445.32 & 1.000 \\
\hline Hainan & 3551.88 & 1413.90 & 1.000 \\
\hline Chongqing & $11,192.65$ & 4293.23 & 0.931 \\
\hline Sichuan & $26,723.52$ & $12,242.07$ & 0.966 \\
\hline Guizhou & $12,394.14$ & 6148.63 & 0.986 \\
\hline Yunnan & $14,625.61$ & 7247.29 & 0.992 \\
\hline Shaanxi & $14,914.46$ & 5984.64 & 0.890 \\
\hline Gansu & 8694.33 & 4254.82 & 0.984 \\
\hline Qinghai & 1974.75 & 1169.92 & 0.987 \\
\hline Ningxia & 3162.34 & 1499.73 & 0.945 \\
\hline Xinjiang & 8397.38 & 3677.73 & 0.970 \\
\hline
\end{tabular}

${ }^{*} \mathrm{CO}_{2}$ emission; ${ }^{* *}$ t.c., tons of carbon (the standard unit of $\mathrm{CO}_{2}$ emission); ${ }^{* * *}$ non-fossil fuel; ${ }^{* * * *}$ tce, tons of standard coal (the unified standard unit of heat value).

Table A3. Multiple iterations of data and DEA efficiency values of the third iteration.

\begin{tabular}{|c|c|c|c|}
\hline Province & $\mathrm{CO}_{2}{ }^{*}\left(10\right.$ Thousand t.c. $\left.{ }^{* *}\right)$ & NFF $* * *\left(10\right.$ Thousand tce $\left.{ }^{* * *}\right)$ & DEA Efficiency Value \\
\hline Beijing & $14,494.35$ & 2945.66 & 1.000 \\
\hline Tianjin & $10,327.37$ & 2413.56 & 0.998 \\
\hline Hebei & $26,463.97$ & $10,042.87$ & 1.000 \\
\hline Shanxi & $13,957.53$ & 5751.81 & 0.993 \\
\hline Inner Mongolia & $19,856.89$ & 7068.50 & 0.997 \\
\hline Liaoning & $24,769.18$ & 7695.29 & 0.999 \\
\hline Jilin & 9844.67 & 4096.97 & 1.000 \\
\hline Heilongjiang & $13,625.17$ & 5693.33 & 0.987 \\
\hline Shanghai & $17,458.65$ & 3948.93 & 0.998 \\
\hline Jiangsu & $46,879.16$ & $11,764.98$ & 0.991 \\
\hline Zhejiang & $28,819.88$ & 7980.42 & 0.984 \\
\hline Anhui & $20,603.08$ & 9391.06 & 0.992 \\
\hline Fujian & $16,481.85$ & 6150.41 & 0.994 \\
\hline Jiangxi & $14,109.97$ & 7145.75 & 1.000 \\
\hline Shandong & $49,261.04$ & $14,820.63$ & 0.994 \\
\hline Henan & $32,460.95$ & $14,499.41$ & 0.992 \\
\hline Hubei & $21,039.75$ & 9010.38 & 0.951 \\
\hline Hunan & $24,120.19$ & 9301.94 & 0.981 \\
\hline Guangdong & $44,301.63$ & $16,545.26$ & 1.000 \\
\hline Guangxi & $15,610.38$ & 7917.95 & 1.000 \\
\hline Hainan & 3682.78 & 1545.63 & 1.000 \\
\hline Chongqing & $10,785.09$ & 4398.78 & 0.962 \\
\hline Sichuan & $27,118.66$ & $12,536.59$ & 0.993 \\
\hline Guizhou & $12,797.92$ & 5937.17 & 0.993 \\
\hline Yunnan & $15,140.85$ & 7256.39 & 0.996 \\
\hline Shaanxi & $14,314.12$ & 5522.64 & 0.975 \\
\hline Gansu & 8973.79 & 4093.72 & 0.992 \\
\hline Qinghai & 2065.16 & 862.15 & 0.983 \\
\hline Ningxia & 3126.23 & 1308.54 & 0.991 \\
\hline Xinjiang & 8644.70 & 3368.66 & 0.984 \\
\hline
\end{tabular}

${ }^{*} \mathrm{CO}_{2}$ emission; ${ }^{* *}$ t.c., tons of carbon (the standard unit of $\mathrm{CO}_{2}$ emission); ${ }^{* *}$ non-fossil fuel; ${ }^{* * * *}$ tce, tons of standard coal (the unified standard unit of heat value). 
Table A4. Multiple iterations of data and DEA efficiency values of the fourth iteration.

\begin{tabular}{|c|c|c|c|}
\hline Province & $\mathrm{CO}_{2}{ }^{*}\left(10\right.$ Thousand t.c. $\left.{ }^{* *}\right)$ & NFF $* * *\left(10\right.$ Thousand tce $\left.{ }^{* * * *}\right)$ & DEA Efficiency Value \\
\hline Beijing & $14,804.30$ & 2989.40 & 1.000 \\
\hline Tianjin & $10,546.46$ & 2429.06 & 1.000 \\
\hline Hebei & $27,035.10$ & $10,194.00$ & 1.000 \\
\hline Shanxi & $14,168.89$ & 5732.73 & 1.000 \\
\hline Inner Mongolia & $20,280.97$ & 7114.08 & 1.000 \\
\hline Liaoning & $25,302.13$ & 7788.75 & 1.000 \\
\hline Jilin & 9920.65 & 4067.13 & 1.000 \\
\hline Heilongjiang & $13,732.40$ & 5667.71 & 1.000 \\
\hline Shanghai & $17,831.06$ & 3977.07 & 1.000 \\
\hline Jiangsu & $45,195.59$ & $12,000.87$ & 0.996 \\
\hline Zhejiang & $27,877.03$ & 8055.46 & 0.996 \\
\hline Anhui & $20,885.81$ & 9433.86 & 1.000 \\
\hline Fujian & $16,754.24$ & 5591.25 & 0.992 \\
\hline Jiangxi & $14,411.70$ & 7251.86 & 1.000 \\
\hline Shandong & $50,107.18$ & $14,911.47$ & 1.000 \\
\hline Henan & $32,525.46$ & $14,718.75$ & 1.000 \\
\hline Hubei & $20,166.37$ & 8775.93 & 0.991 \\
\hline Hunan & $21,824.64$ & $10,122.70$ & 0.997 \\
\hline Guangdong & $45,404.14$ & $15,002.36$ & 0.992 \\
\hline Guangxi & $15,944.75$ & 8022.99 & 1.000 \\
\hline Hainan & 3761.54 & 1568.58 & 1.000 \\
\hline Chongqing & $10,079.15$ & 4486.44 & 0.991 \\
\hline Sichuan & $27,241.40$ & $12,736.98$ & 1.000 \\
\hline Guizhou & $12,985.58$ & 5945.07 & 1.000 \\
\hline Yunnan & $15,399.52$ & 7302.29 & 1.000 \\
\hline Shaanxi & $13,896.83$ & 5592.89 & 0.998 \\
\hline Gansu & 9094.69 & 4088.80 & 1.000 \\
\hline Qinghai & 2078.78 & 827.31 & 1.000 \\
\hline Ningxia & 3188.30 & 1299.54 & 1.000 \\
\hline Xinjiang & 8690.36 & 3320.05 & 1.000 \\
\hline
\end{tabular}

${ }^{*} \mathrm{CO}_{2}$ emission; ${ }^{* *}$ t.c., tons of carbon (the standard unit of $\mathrm{CO}_{2}$ emission); ${ }^{* * *}$ non-fossil fuel; ${ }^{* * * *}$ tce, tons of standard coal (the unified standard unit of heat value).

Table A5. Multiple iterations of data and DEA efficiency values of the fifth iteration.

\begin{tabular}{|c|c|c|c|}
\hline Province & $\mathrm{CO}_{2}{ }^{*}\left(10\right.$ Thousand t.c. $\left.{ }^{* *}\right)$ & NFF $* * *\left(10\right.$ Thousand tce $\left.{ }^{* * *}\right)$ & DEA Efficiency Value \\
\hline Beijing & $14,921.51$ & 2988.12 & 1.000 \\
\hline Tianjin & $10,629.96$ & 2427.85 & 1.000 \\
\hline Hebei & $27,248.99$ & $10,189.57$ & 1.000 \\
\hline Shanxi & $14,281.07$ & 5730.28 & 1.000 \\
\hline Inner Mongolia & $20,441.53$ & 7111.03 & 1.000 \\
\hline Liaoning & $25,502.38$ & 7785.88 & 1.000 \\
\hline Jilin & $10,000.10$ & 4066.37 & 1.000 \\
\hline Heilongjiang & $13,843.62$ & 5667.44 & 1.000 \\
\hline Shanghai & $17,972.23$ & 3975.49 & 1.000 \\
\hline Jiangsu & $45,101.71$ & $12,000.64$ & 1.000 \\
\hline Zhejiang & $27,138.91$ & 8211.68 & 1.000 \\
\hline Anhui & $21,055.40$ & 9433.53 & 1.000 \\
\hline Fujian & $16,743.07$ & 5501.59 & 1.000 \\
\hline Jiangxi & $14,525.79$ & 7248.75 & 1.000 \\
\hline Shandong & $48,333.68$ & $15,418.65$ & 1.000 \\
\hline Henan & $32,782.57$ & $14,693.31$ & 1.000 \\
\hline Hubei & $20,136.15$ & 8639.18 & 1.000 \\
\hline Hunan & $21,919.79$ & $10,000.77$ & 1.000 \\
\hline Guangdong & $45,344.96$ & $14,847.41$ & 1.000 \\
\hline Guangxi & $16,070.98$ & 8019.55 & 1.000 \\
\hline Hainan & 3791.32 & 1567.91 & 1.000 \\
\hline Chongqing & $10,068.19$ & 4424.33 & 1.000 \\
\hline Sichuan & $27,454.56$ & $12,719.79$ & 1.000 \\
\hline Guizhou & $13,089.43$ & 5943.99 & 1.000 \\
\hline Yunnan & $15,522.51$ & 7300.71 & 1.000 \\
\hline Shaanxi & $13,979.34$ & 5569.38 & 1.000 \\
\hline Gansu & 9167.05 & 4087.65 & 1.000 \\
\hline Qinghai & 2094.95 & 826.50 & 1.000 \\
\hline Ningxia & 3213.47 & 1298.73 & 1.000 \\
\hline Xinjiang & 8759.82 & 3319.33 & 1.000 \\
\hline
\end{tabular}

${ }^{*} \mathrm{CO}_{2}$ emission; ${ }^{* *}$ t.c., tons of carbon (the standard unit of $\mathrm{CO}_{2}$ emission); ${ }^{* *}$ non-fossil fuel; ${ }^{* * * *}$ tce, tons of standard coal (the unified standard unit of heat value). 


\section{References}

1. Ding, D.; Feng, J. The choices of the carbon allowances allocation methods in our country. Int. Bus. 2013, 4, 83-92.

2. Sun, D.; Ma, X. The research of the methods of initial allocation of carbon allowances. Ecol. Econ. 2013, 2, $81-85$.

3. Yin, Y.; Cui, M. The research of "China plan" in the international carbon financial system construction. Int. Financ. Res. 2010, 12, 59-66.

4. Wang, Y. The Way of Carbon Emissions Trading System of China: International Practice and Application in China; Economics and Management Press: Beijing, China, 2011.

5. Jiang, J. On carbon quota distribution on a limited rationality repeat gam e. China Open. J. 2013, 3, 18-35. (In Chinese)

6. Cong, R. The design of carbon allowance auction mechanism: Based on the research on multi-agents model. Rev. Econ. Prod. 2013, 1, 113-124.

7. Wang, K.; Li, M. The DEA model and application of carbon emission allocation. J. Beijing Inst. Technol. 2013, 4, 7-13.

8. Rogge, K.S.; Hoffmann, V.H. The impact of the EU ETS on the sectoral innovation system for power generation technologies-Findings for germany. Energy Policy 2010, 38, 7639-7652. [CrossRef]

9. Sandoff, A.; Schaad, G. Does EU ETS lead to emission reductions through trade? The case of the Swedish emissions trading sector participants. Energy Policy 2009, 37, 3967-3977. [CrossRef]

10. Zhang, Y.-J.; Wei, Y.-M. An overview of current research on EU ETS: Evidence from its operating mechanism and economic effect. Appl. Energy 2010, 87, 1804-1814. [CrossRef]

11. Oestreich, A.M.; Tsiakas, I. Carbon emissions and stock returns: Evidence from the EU emissions trading scheme. J. Bank. Financ. 2015, 58, 294-308. [CrossRef]

12. Jong, T.; Couwenberg, O.; Woerdman, E. Does EU emissions trading bite? An event study. Energy Policy 2014, 69, 510-519. [CrossRef]

13. Bushnell, J.B.; Chong, H.; Mansur, E.T. Profiting from regulation: Evidence from the European carbon market. Am. Econ. J. Econ. Policy 2013, 5, 78-106. [CrossRef]

14. Zeng, S.; Hu, M.; Su, B. Research on investment efficiency and policy recommendations for the culture industry of China based on a three-stage DEA. Sustainability 2016, 8, 324. [CrossRef]

15. Zofi'o, J.L.; Prieto, A.M. Environmental efficiency and regulatory standards: The case of $\mathrm{CO}_{2}$ emissions from OECD industries. Resour. Energy Econ. 2001, 23, 63-83. [CrossRef]

16. Lozano, S.; Gutiérrez, E. Non-parametric frontier approach to modelling the relationships among population, GDP, energy consumption and $\mathrm{CO}_{2}$ emissions. Ecol. Econ. 2008, 66, 687-699. [CrossRef]

17. Lins, M.P.E.; Gomes, E.G.; De Mello, J.C.C.B.S.; De Mello, A.J.R.S. Olympic ranking based on a zero sum gains DEA model. Eur. J. Oper. Res. 2003, 148, 312-322. [CrossRef]

18. Lin, T.; Ning, J. The research on the carbon emission permit allocative efficiency in EU countries based on zero and DEA model. J. Quant. Tech. Econ. 2011, 3, 36-50.

19. Sun, Z.; Zhou, D.; Zhou, P.; Miao, Z. The allocation of the energy-saving index based on the environment ZSG-DEA. Syst. Eng. 2012, 1, 84-90.

20. Wu, X.; Tan, L.; Guo, J.; Wang, Y.; Liu, H.; Zhu, W. A study of allocative efficiency of PM2.5 emission rights based on a zero sum gains data envelopment model. J. Clean. Prod. 2016, 113, 1024-1031. [CrossRef]

21. Pang, R.-Z.; Deng, Z.-Q.; Chiu, Y.-H. Pareto improvement through a reallocation of carbon emission quotas. Renew. Sustain. Energy Rev. 2015, 50, 419-430. [CrossRef]

22. Wang, K.; Zhang, X.; Wei, Y.-M.; Yu, S. Regional allocation of $\mathrm{CO}_{2}$ emissions allowance over provinces in China by 2020. Energy Policy 2013, 54, 214-229. [CrossRef]

23. Miao, Z.; Geng, Y.; Sheng, J. Efficient allocation of $\mathrm{CO}_{2}$ emissions in China: A zero sum gains data envelopment model. J. Clean. Prod. 2016, 112, 4144-4150. [CrossRef]

24. Tietenberg, T. The tradable-permits approach to protecting the commons: Lessons for climate change. Oxf. Rev. Econ. Policy 2003, 19, 400-419. [CrossRef]

25. Fischer, C. Combining rate-based and cap-and-trade emissions policies. Clim. Policy 2003, 3, S89-S103. [CrossRef] 
26. Quirion, P. Historic versus output-based allocation of GHG tradable allowances: A comparison. Clim. Policy 2009, 9, 575-592. [CrossRef]

27. Fischer, C.; Fox, A.K. Output-based allocation of emissions permits for mitigating tax and trade interactions. Land Econ. 2007, 83, 575-599. [CrossRef]

28. Yuan, Y.-N.; Shi, M.-J.; Li, N.; Zhou, S.-L. Intensity allocation criteria of carbon emissions permits and regional economic development in China-Based on a 30-province/autonomous region computable general equilibrium model. Adv. Clim. Chang. Res. 2012, 3, 154-162.

29. Xu, J.; Yang, X.; Tao, Z. A tripartite equilibrium for carbon emission allowance allocation in the power-supply industry. Energy Policy 2015, 82, 62-80. [CrossRef]

30. Paloheimo, E.; Salmi, O. Evaluating the carbon emissions of the low carbon city: A novel approach for consumer based allocation. Cities 2013, 30, 233-239. [CrossRef]

31. Zhang, Y.-J.; Wang, A.-D.; Da, Y.-B. Regional allocation of carbon emission quotas in China: Evidence from the shapley value method. Energy Policy 2014, 74, 454-464. [CrossRef]

32. Yu, S.; Wei, Y.-M.; Wang, K. Provincial allocation of carbon emission reduction targets in China: An approach based on improved fuzzy cluster and shapley value decomposition. Energy Policy 2014, 66, 630-644. [CrossRef]

33. Pan, X.; Teng, F.; Ha, Y.; Wang, G. Equitable access to sustainable development: Based on the comparative study of carbon emission rights allocation schemes. Appl. Energy 2014, 130, 632-640. [CrossRef]

34. Gao, G.; Chen, S.; Yang, J. Carbon emission allocation standards in China: A case study of Shanghai city. Energy Strategy Rev. 2015, 7, 55-62. [CrossRef]

35. Feng, C.; Chu, F.; Ding, J.; Bi, G.; Liang, L. Carbon emissions abatement (CEA) allocation and compensation schemes based on DEA. Omega 2015, 53, 78-89. [CrossRef]

36. Ren, J.; Bian, Y.; Xu, X.; He, P. Allocation of product-related carbon emission abatement target in a make-to-order supply Chain. Comput. Ind. Eng. 2015, 80, 181-194. [CrossRef]

37. Gomes, E.G.; Lins, M.P.E. Modelling undesirable outputs with zero sum gains data envelopment analysis models. J. Oper. Res. Soc. 2008, 59, 616-623. [CrossRef]

38. The National Bureau of Statistics. China Energy Statistical Yearbook; China Statistics Press: Beijing, China, 2011.

39. The National Bureau of Statistics. China Energy Statistical Yearbook 2013; China Statistics Press: Beijing, China, 2013.

40. The National Bureau of Statistics. China Statistical Yearbook 2011; China Statistics Press: Beijing, China, 2011.

41. The National Bureau of Statistics. China Statistical Yearbook 2012; China Statistics Press: Beijing, China, 2012.

42. The National Bureau of Statistics. China Statistical Yearbook 2013; China Statistics Press: Beijing, China, 2013.

43. The National Bureau of Statistics. China Statistical Yearbook 2014; China Statistics Press: Beijing, China, 2014.

44. The National Bureau of Statistics. China Statistical Yearbook 2015; China Statistics Press: Beijing, China, 2015.

45. The Department of Dealing with Climate Changes in National Development and Reform Commission. Greenhouse Gases at the Provincial Level Listing Compilation Guidelines. 2011. Available online: http://www.cbcsd.org.cn/sjk/nengyuan/standard/home/20140113/download/shengjiwenshiqiti.pdf (accessed on 28 April 2016).

46. Sun, T.; Zhao, T. The research on measurement of carbon emission and its trend. Audit. Econ. Res. 2014, 2, 104-111.

47. Chinese Electricity Business Council. The Annual Report of the Development of Chinese Electricity Industry in 2011; China Market Press: Beijing, China, 2011.

48. China's National Standard Management Committee. The General Principles of the Comprehensive Energy Consumption Calculation(GB/T 2589-2008); China Standard Publishing House: Beijing, China, 2008.

49. Energy Information Administration (EIA). International Energy Outlook 2009; Energy Information Administration: Washington, DC, USA, 2009.

50. World Population Prospects: The 2008 Revision. Un Department of Economic and Social Affairs; United Nations Department of Economic and Social Affairs (UNDESA): New York, NY, USA, 2009.

(C) 2016 by the authors; licensee MDPI, Basel, Switzerland. This article is an open access article distributed under the terms and conditions of the Creative Commons Attribution (CC-BY) license (http://creativecommons.org/licenses/by/4.0/). 